\title{
A peer led asthma education programme in adolescents was more effective than no programme for improving quality of life
}

\author{
Shah S, Peat JK, Mazurski EJ, et al. Effect of peer led programme for asthma education in adolescents: cluster randomised \\ controlled trial. BMJ 2001 Mar 10;322:583-5.

\section{QUESTION: In adolescents with asthma, is a peer led asthma education programme more effective than no programme for improving quality of life $(\mathrm{QoL})$ ?}

Design

Randomised (allocation concealed*), blinded \{data analyst $\} \uparrow, *$ controlled trial with 3 months follow up.

\section{Setting}

6 high schools in Tamworth, New South Wales, Australia.

\section{Patients}

272 adolescents who were in grades 7 and 10, were present on the test day, and reported recent wheeze were included in the study. 251 adolescents (92\%; mean age $14 \mathrm{y}, 55 \%$ girls) completed follow up.

\section{Intervention}

3 schools (124 students) were cluster randomised to implement the adolescent peer led asthma education (Triple A) programme. The Triple A programme involved a 3 step approach to peer led education. In step 1 , student volunteers in grade 11 were trained as leaders during a 6 hour workshop to educate their peers on asthma and its management; in step 2, teams of 3-4 of these leaders taught three 45 minute health lessons to grade 10 classes in their schools on how to critically analyse the barriers to asthma management by using games, videos, worksheets, and discussion; and in step 3, the grade 10 students developed short acts, dramas, and songs to present the key messages to grade 7 students. 3 schools (148 students) were cluster randomised to receive no programme.

\section{Main outcome measures}

Main outcomes included asthma QoL (overall, activities, symptoms, and emotions) and lung function. QoL was assessed using a self administered questionnaire. Improvement in QoL was considered clinically important with a change in score of $>0.5$ units.

Department of Health

and Aged Care and

Asthma NSW.

For correspondence: Dr S Shah, Department of Public Health and Community Medicine, Westmead Hospital, Westmead, NSW 2145 , Australia. Fax +612 96891049 .

\section{Main results}

Overall QoL and activities were higher for students in the Triple A programme than for those who were not (table). Grade 10 students in the Triple A programme reported an increase in $\mathrm{QoL}(\mathrm{p}=0.01)$ (table), and grade 7 students did not $(p=0.08)$. Grade 7 students in the

Adolescent peer led asthma education programme (Triple A) v no programme for overall quality of life (QoL) and QoL activities domain

\begin{tabular}{lllll}
$\begin{array}{l}\text { Outcomes at } 3 \\
\text { months }\end{array}$ & Triple A & $\begin{array}{l}\text { No } \\
\text { programme }\end{array}$ & RBI (95\% Cl) & NNT (Cl) \\
\hline Overall QoL & $25 \%$ & $12 \%$ & $101 \%(17$ to 247$)$ & 8 (5 to 36$)$ \\
\hline Grade 10 QoL & $18 \%$ & $4.5 \%$ & $306 \%(31$ to 1200$)$ & $8 \S(5$ to 32$)$ \\
\hline Overall activities & $41 \%$ & $28 \%$ & $48 \%(4.3$ to 110$)$ & 8 (5 to 72$)$ \\
\hline Grade 7 activities & $55 \%$ & $30 \%$ & $87 \%(21$ to 192$)$ & 4 (3 to 13$)$ \\
\hline
\end{tabular}

$\ddagger$ Abbreviations defined in glossary; $\mathrm{RBI}, \mathrm{NNT}$, and $\mathrm{Cl}$ calculated from data in article.

§NNT rounded to the next highest integer.

Triple A programme reported an increase in activities $(\mathrm{p}=0.005) \quad$ (table), and grade 10 students did not $(\mathrm{p}=0.53)$. Groups did not differ for emotions $(\mathrm{p}=0.14)$ or symptoms $(p=0.15)$. Groups did not differ for improved lung function.

\section{Conclusion}

In adolescents with asthma, a peer led asthma education programme was more effective than no programme for improving overall quality of life and activities.

*See glossary.

†nformation provided by author.

\section{COMMENTARY}

Current asthma consensus guidelines consider asthma education to be one of the most important components of asthma management, but unfortunately, this aspect of care is often neglected. Furthermore, we need to determine what types of educational interventions are most useful in the various subgroups of patients with asthma, such as adolescents. The study by Shah et al reports a new and promising approach to providing asthma education to adolescents through a peer led programme. It suggests that adolescents can learn from their peers and probably do so more often than from adult educators. Lung function improved in both groups. Because the intervention was done at the same time as the control group, the magnitude of the effect may have been underestimated as a result of contamination of the control group through awareness of the study in the community.

The level of asthma related morbidity in these adolescents seemed low; if a high morbidity subgroup had been chosen, the results might have been more striking. ${ }^{1}$ It would be worth repeating the study among adolescents who have recently visited an emergency room for acute asthma, as we recently did for adults. ${ }^{2}$ Furthermore, high morbidity groups are often non-attenders of educational programmes, and new initiatives, such as the one described by Shah $e t$ al, could be useful in motivating these patients to improved self management.

This study is important because it suggests the peer teaching approach that has been successful in drug use prevention among adolescents ${ }^{3}$ may be transferable to asthma education.

Louis-Philippe Boulet, MD Université Laval Québec City, Québec, Canada

1 Boulet LP. Asthma education: what has been its impact? Can Respir J 1998;5(suppl A):91-6A.

2 Cote J, Bowie DM, Robichaud P, et al. Evaluation of two different educational interventions for adult patients consulting with an acute asthma exacerbation. Am J Respir Crit Care Med 2001;163:1415-9.

3 Tobler NS. Drug prevention programs can work: research findings. J Addict Dis 1992;11:1-28. 